\title{
El novedoso concepto de familia influenciado por las técnicas de reproduccion asistida (T.R.A) en Colombia:
}

Con un especial énfasis en la conformación de las familias homoparentales a través de las T.R.A.

The new concept of family influenced by the Techniques of Assisted Reproduction (T.A.R.) in Colombia:

With a special emphasis on the conformation of homoparental

families through the T.A.R.

Vanina Moadie Ortega

"La ciencia ha proporcionado al hombre innumerables beneficios, ha disipado engaños, y ha permitido que la inteligencia del ser humano contemple con mayor asombro el vasto universo que todavía queda por descubrir."

M.P.V

\section{Resumen}

A partir de la expedición de la Carta Política Colombiana de 1991, se establece la posibilidad de existencia de hijos con asistencia científica, por lo que a través de una investigación de enfoque cualitativa, tipo dogmático, y con técnicas de recolección de información documental, se plantea una novedosa forma de configuración familiar a través de la utilización de las técnicas de reproducción humana asistida, enfatizando en la configuración familiar homoparental, y en el tránsito de la "familia homoparental" al "matrimonio igualitario en Colombia", por lo que se abordan los desafíos jurídicos que enfrentan las familias biparentales y homoparentales para acceder a las técnicas de reproducción humana asistida, distinguiendo entre parejas homosexuales femeninas y masculinas, para finalmente plantear conclusiones.

Palabras claves: Familia, técnicas de reproducción humana asistida, familia homoparental.

\section{Abstracts}

Since the issuance of the Colombian Political Charter of 1991, it is established the possibility of children with scientific assistance, so that through a qualitative research, dogmatic type, and with collection techniques of documentary information, a novel form of family configuration is proposed through the use of assisted human reproduction techniques, emphasizing homoparental family configuration and the transition from "homoparental family" to "equal marriage in Colombia" This study addresses the legal challenges faced by biparental and homoparental families in accessing assisted reproductive techniques, distinguishing between female and male homosexual couples, in order to reach conclusions.

Keywords: Family, techniques of assisted human reproduction, homoparental family.

1 Abogada, Magister en Derecho de la Universidad de Medellín, Investigadora del Grupo de Investigaciones Sociales y Jurídicas del Programa de Derecho de la Fundación Universitaria Tecnológico Comfenalco-Cartagena en Convenio con la Universidad de Medellín. Correo electrónico: vmoadie@tecnologicocomfenalco.edu.co. 


\section{INTRODUCCIÓN}

En la época de expedición del Código Civil Colombiano era impensable que un niño fuese concebido luego de muerto su padre; dado los avances de la ciencia médica a través de las técnicas de reproducción humana asistida, en especial con la crioconservación del semen, es posible que en la actualidad algunas mujeres soliciten ser inseminadas con el semen de su marido muerto, técnica que es conocida como "fecundación post-mortem", siendo esta apenas una -quizá la más controvertida y de reciente creación- de las varias técnicas de reproducción humana asistida.

De igual manera podemos pensar el caso de un menor que nazca con el semen de un donante, óvulos de una donante, a través de la inseminación artificial, pero gestado a través de un arrendamiento de vientre,(esto es, con la utilización de dos ( 2) técnicas de reproducción asistida -T.R.A-); pero además se le puede dar otra visión si observamos que el anterior ejemplo puede ser motivado por una pareja heterosexual para dar paso a una familia biparental a través de técnicas de reproducción humana asistida, o por una pareja homosexual masculina(gays) para dar paso una familia homoparental a través de técnicas de reproducción humana asistida.

La ausencia de regulación sobre las técnicas de la reproducción humana asistida en Colombia es una realidad innegable, de la cual no podemos hacer abstracción. El derecho positivo ha sido desbordado por los adelantos biotecnológicos y médicos, ubicándolo en desventaja frente a temas no reglamentados (Moadie, 2014), que podrían tener incidencia en torno a los aspectos tradicionales en la conformación de la familia, y en especial en el derrumbamiento del concepto tradicional de familia.

\section{JUSTIFICACIÓN}

Aun así, a partir de lo planteado en el acápite anterior, se debe resaltar que en Colombia desde la expedición de la Carta Política Colombiana de 1991 se establece la "posibilidad de existencia de hijos con asistencia científica"; el artículo 42 de la Carta Magna define la familia como "el núcleo fundamental de la sociedad y que se constituye por vinculos naturales o jurídicos, por la decisión libre de un hombre y una mujer de contraer matrimonio 0 por la voluntad responsable de conformarla", y en el inciso 5 de dicho artículo manifiesta que "Los hijos habidos en el matrimonio o fuera de él, adoptados o procreados naturalmente o con asistencia científica, tienen iguales derechos y deberes." (Las negrillas y el subrayado es propio, a propósito de las énfasis que tendrá el presente artículo)

Lo anterior indica que el constituyente otorga igualdad a los hijos ya procreados naturalmente, ya adoptados o ya procreados a través de asistencia científica -lo que en este momento nos ocupa-, y manifiesta que la ley reglamentara la progenitura responsable; lo cuestionable es que si bien la Constitución Política colombiana establece la posibilidad de existencia de hijos con asistencia cientíica, hoy, 23 años $^{\star 2}$ después de expedida la Carta Magna no exista ley alguna que reglamente las técnicas de reproducción asistida.... lo que evidencia la relevancia e importancia de la temática. (Moadie, 2014).

Si bien podemos afirmar que existe una amplia literatura sobre el aspecto ético, científico, moral, y bioético de las técnicas de reproducción asistida en el mundo y en Colombia, en esta ocasión se pretende evidenciar el planteamiento de una realidad que podría incidir en una nueva concepción de familia, toda vez que uno de los roles de toda familia es la procreación- aunque también fue concebida como uno de los fines del matrimonio según el art. 113 del Código Civil Colombiano-, y las técnicas de procreación humana asistidas fueron pensadas inicialmente y desarrolladas como un aporte de la ciencia médica ante la dificultad de algunos matrimonios para la procreación, concebidas estas como "el conjunto de técnicas médicas especiales que implican la ayuda profesional al acto conyugal con el fin de de lograr la procreación de la especie humana, la obtención y utilización de gametos con tal finalidad, o la transferencia de embriones con el mismo fin". En una definición más neutral, y sin énfasis en el matrimonio, Santamaria (2000), afirma que las Técnicas de Reproducción Humana Asistida, son "el Conjunto de métodos biomédicos, que conducen a facilitar, o substituir, a los procesos biológicos naturales que se desarrollan durante la procreación humana".

Es menester manifestar, que en los países que cuentan con avanzadas y actuales legislaciones, las técnicas de procreación humana asistidas están permitidas no necesariamente para matrimonios, sino para parejas sin e

2 Hoy serian 25 años, teniendo en cuanto que se realiza la autocita de un articulo publicado en 2014.

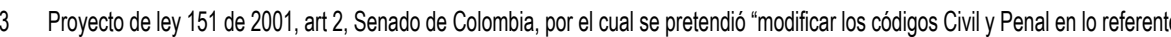

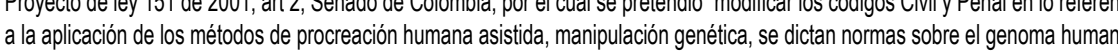
de nuestra diversidada éticica, y yraas disposiciones" 
mencionado vinculo, o aun para la utilización de personas individuales, o para parejas del mismo sexo, lo cual se retomará en el desarrollo de este artículo.

Sin lugar a dudas, entonces, el tema que se pretende desarrollar se plantea como una nueva posibilidad de creación de familias, que arriesgadamente hemos llamado FAMILIAS PROCREADAS CON ASISTENCIA CIENTIFICA ${ }^{4}$, evidenciando que si bien es cierto que existen diversas clases de familias sobre las que se ha legislado y sobre las cuales existe una amplia gama de literatura doctrinaria y jurisprudencial, también hay algunas tipologías de familias sobre las cuales no hay pronunciamiento ni cobertura o protección legal, estas serían las FAMILIAS HOMOPARENTALES CONFORMADAS CON TECNICAS DE REPRODUCCION HUMANA ASISTIDA, sobre las cuales se debe aclarar, que en relación con la "familia homoparental" si hay pronunciamientos, pero NO existen dichos pronunciamientos en relación con la mezcla de las dos categorías, a saber: una primera categoría de familia homoparental y una segunda categoría de utilización de técnicas de reproducción asistida ( T.R.A.) para la conformación de dicha familia, para así llegar al énfasis prometido en el título de este artículo que es: "la conformación de las familias homoparentales a través de las T.R.A."

\section{PLANTEAMIENTO DEL PROBLEMA Y METOdOLOGÍA}

La reflexión teórica presentada en este artículo se plantea como avance de investigación del proyecto denominado: "Disponibilidad Jurídica del cuerpo humano en el ordenamiento Jurídico Colombiano", que es desarrollado por el semillero de Derecho Privado en la línea de Derecho y Sociedad del Grupo de Investigaciones Sociales y Jurídicas de la Fundación Universitaria Tecnológico Comfenalco-Cartagena. y en el cual se ha construido inicialmente como problema jurídico el siguiente: “ $¿$ Existe en el ordenamiento jurídico colombiano fundamentos que permitan una regulación sobre la disponibilidad jurídica del cuerpo humano y partes separadas de este ${ }^{5}$, como respuesta a los avances científicos propiciados por la ciencia médica?, y de igual manera tributa al desarrollo de un nuevo proyecto de investigación en curso denominado "Técnicas de procreación con asistencia científica en relación al enfoque de género", que es desarrollado por la fusión de los semilleros "de 4 Teniendo en cuenta que asi se le llamo a las técnicas de reproducción humana asistida en la Constitución Pollitica

En este punto se encuentra el enlace con el tema desarrollado, entendiendo la disposición del vientre, semen
yóvulos como disposición del cuerpo humano y partes sanpardas del cuerpo as como las implicaiones que dichad disposición tiene, por tratarerse de organanos y y fluidos corporales que permite, la reproduccición humana asistida. derecho privado" y semillero "nuevo género", de la Fundación Universitaria Tecnológico Comfenalco-Cartagena, donde se plantea como problema jurídico: ¿Qué desafíos jurídicos enfrentan las técnicas de procreación con asistencia científica en relación con el enfoque de género?, y se plantea como objetivo general Analizar las técnicas de procreación con asistencia científica en relación al enfoque de género.

La metodología implementada es de enfoque cualitativa, de tipo dogmático, que utiliza como técnica de recolección de información la revisión documental, acudiendo a fuentes primarias y secundarias.

\section{DESARROLLO: AVANCES Y DISCUSIONES}

A continuación, se realizará inicialmente un abordaje sobre las técnicas de reproducción humana asistida en general, con el fin de plantear unas premisas básicas para el entendimiento del tema, posteriormente se dará paso a analiza la forma en que las familias son conformadas a través de procreación científica en Colombia señalando un breve resumen de casuística en Colombia a través de señalización de casos paradigmáticos asumiendo una postura crítica frente a las soluciones planteadas por fallos o sobre la ausencia de fallos que resuelvan a través de tres (3) de las técnicas de reproducción humana asistida( Inseminación Artificial.( I.A), Arrendamiento de vientre y Fecundación post-mortem); luego se hará un abordaje el concepto constitucional de familia a través de pronunciamientos de la Corte Constitucional Colombiana así como el abordaje de lo que hemos denominado las familias homoparentales, y se planteará el tema de la CONFIGURACION FAMILIAR HOMOPARENTAL evidenciando el tránsito de la "familia homoparental" al "matrimonio igualitario en Colombia(La histórica sentencia SU 214 de 2016),para plantear finalmente el acceso a las técnicas de Reproducción asistida, como un desafí para las parejas heterosexuales y homosexuales, haciéndose énfasis en una breve distinción entre las técnicas propicias para las parejas homosexuales femeninas (lesbianas) y para las parejas homosexuales masculinas(gays).

\section{De las técnicas de reproducción humana asistida en general}

En general la procreación a través de asistencia cientíica, como lo denomin Colombia, en el citado art 42 de la Constitución, es lo que países como España y Argentina han denominado técnicas de reproducción humana asistida (TRHA) o técnicas de procreación medica asistida (PMA) como lo denomina Italia, o 
procreación artificial (PA) como lo denominó Francia; al parecer según nuestro texto Constitucional, en Colombia debería llamarse técnicas de procreación con asistencia científica. ( TPAC).

Flores Salgado (2007), menciona como técnicas de reproducción asistida (T.R.A), las siguientes: i) La inseminación artificial, ii) La fecundación in vitro: transferencia de embriones producidos en el laboratorio y iii) La maternidad por sustitución, subrogada o de alquiler, consistente en el alquiler del útero para la gestación del menor.

Las actuales técnicas de reproducción asistida (T.R.A) se reducen, según Sarmiento M.(2009), a la inseminación artificial (IA), la fecundación in vitro con embriotransferencia (FIVET) y la inyección espermática intracitoplasmática de espermatozoides (ICSI), considerando además que los demás nombres son variaciones de estas, que describen procedimientos similares usados con fines de reproducción extracorpórea.

La actual legislación Española, ley 14/2006, señaló como técnicas de reproducción asistida: (1) la inseminación artificial, (2) la fecundación in vitro e inyección intracitoplásmica de espermatozoides procedentes de eyaculado, con gametos propios o de donante y con transferencia de preembriones y (3) La transferencia intratubárica de gametos; pero manifiesta la mencionada ley, que el Gobierno mediante real decreto y previo informe de la Comisión Nacional de Reproducción Humana Asistida, podrá actualizar la lista para la adaptación a los avances científicos y técnicos y para incorporar aquellas técnicas experimentales que hayan demostrado, mediante experiencia suficiente, reunir las condiciones de acreditación científica y clínica precisas para su aplicación generalizada.

\section{Familias formadas a través de procreación cientifica}

En 2012, cuando Louise Brown alcanzo a sus 34 años de existencia luego de convertirse en 1978 en la primera bebé concebida fuera del útero (bebé probeta), los expertos en fertilidad estimaron que cinco millones de niños alrededor del mundo son el resultado de las técnicas de reproducción asistida.

Comité Internacional para el Monitoreo de la Tecnología de Reproducción Asistida, una organización independiente, internacional y sin fines de lucro que reúne y difunde información internacional, durante la vigesimoctava reunión anual de la Sociedad Europea de Reproducción Humana y Embriología el 1 de julio de 2012, presentó estimaciones sobre el número de partos exitosos resultado de tratamientos de fertilización in vitro e inseminación artificial Se calculó la cifra de cinco millones basándose en "el número de ciclos de tratamientos para IVF e ICSI registrados a nivel mundial hasta el 2008 añadiendo los siguientes tres años.

\section{Familias formadas a través de procreación cientifica en Colombia}

Según datos médicos recopilados por la Fundación Colombiana de Parejas Infértiles (Funcopi), en nuestro país, del $25 \%$ de las personas que están entre la edad de 25 y 35 años (12 millones), que buscan ser padres, un 2 \% (2.5 millones) sufren de infertilidad. Lo cual que demuestra que es necesario y urgente liderar una política médica, para reglamentar los referidos procedimientos e incluirlos en los planes obligatorios de salud.

En otras oportunidades hemos analizado detenidamente CASOS PARADIGMATICOS, donde se planteó una casuística básica de tres de las actuales técnicas de reproducción asistida reconocidas, aceptadas y permitidas a nivel mundial, pero abordando tres( 3 ) casos paradigmáticos en Colombia, asumiendo una postura crítica frente a las soluciones planteadas por el código civil actual en el ámbito filial y sucesoral, o sobre la ausencia de fallos que resuelvan los hechos, a continuación un breve resumen de los mismos:

\section{Inseminación Artificial.( I.A)}

El 28 de febrero de 2013, con ponencia de Arturo Solarte Rodríguez en la sala de casación Civil de la Corte Suprema de Justicia Colombiana, se decidió el recurso extraordinario de casación interpuesto por el Defensor de Familia adscrito al Juzgado Segundo de Familia de Bogotá, en representación del menor demandado, respecto de la sentencia proferida el 25 de enero de 2010 por el Tribunal Superior del Distrito Judicial de Bogotá, Sala de Familia, dentro del proceso ordinario de impugnación de la paternidad que el señor XX iniciare como padre del menor ZXY

El caso refiere que: i)La pareja de cónyuges conformada por XX y YY, durante mucho tiempo, trató de concebir un hijo, lo que no fue posible, debido a que se estableció médicamente que el señor XX "tenía una deficiencia de esperma- 
tozoide[s]", ii)“"Frente a tal situación los esposos XY, estudiaron otras opciones como la inseminación artificial, llegándose a concluir que si el padre no podía concebir, se efectuaría inseminación con espermas del PADRE del demandado señor XX. Los citados esposos, militares de profesión, fueron trasladados a laborar en sedes diferentes al domicilio del hogar y para la época en que la señora YY quedó embarazada, el actor no había iniciado el tratamiento mencionado. Aun así, el menor accionado nació en 2004 y el demandante lo registró como su hijo, pero el señor XX "tiene serios indicios de que el menor no es hijo suyo, dado su estado clínico". iii.-)Admitida la demanda por el Juzgado Segundo de Familia de Bogotá, la progenitora YY del menor accionado, manifestó allanarse a sus pretensiones y frente a la manifestación del actor XX en el sentido de que consideraba que no era padre del niño "porque no ten[ía] la capacidad de concebir [por] un problema biológico", aseveró lo siguiente: "[e]so es cierto, a mí me realizaron una inseminación artificial en el HOSPITAL MILITAR" y decretadas las pruebas del proceso se determinó que "[l]a paternidad del XX con relación al menor Z es Incompatible. iv.-) Agotado el trámite de la primera instancia, la autoridad judicial dictó sentencia el 10 de diciembre de 2008, en la que declaró que "el niño Z, representado por su progenitora YY, nacido en 2004, no era hijo del señor XX; sin saber conocer su verdadero origen, con posible vulneración de la VERDAD PROCREACIONAL 0 VERDAD BIOLOGICA;

En el presente caso, La Corte Suprema de Justicia NO casó la sentencia, pero aun asi manifestó: "la Sala llama la atención sobre el vacío legal existente en el derecho colombiano, toda vez que no hay una normatividad que regule de manera integral los diferentes aspectos jurídicos relacionados con las técnicas de reproducción humana asistida y, en particular, lo atinente al estado civil de las personas fruto de esos avances cientíicos."

\section{Arrendamiento de vientre}

En esta ocasión La Corte Constitucional Colombiana, tuvo la ocasión de pronunciarse sobre el arrendamiento de vientre, en la sentencia T-968 de Diciembre 18 de 2009, con ponencia de la única Magistrada de la Corte, la Dra. María Victoria Calle Correa, sobre en el caso más paradigmático ${ }^{6}$ y más

6 Paradigmático en el sentidid de que se obtuivieron 4 fallos al respecto del mismo caso: El caso futue fallado en primera instancia por el

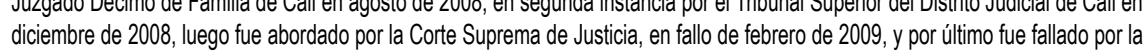

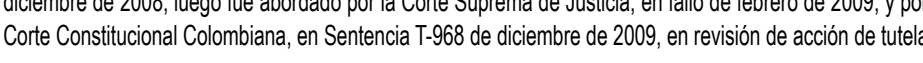

aproximado ${ }^{7}$ a dicho fenómeno, que hasta el momento se haya fallado en Colombia.

Resumen de Hechos: "El caso de los gemelos Samuel y David", que nacieron el día 21 de marzo de 2006 en el municipio de Vijes, como producto de la inseminación artificial consentida, ya que Salomón de nacionalidad colombiana, casado con Raquel, dominicana, residentes en Estados Unidos, deseaban tener un hijo y en un principio Saraí de nacionalidad colombiana aceptó realizarse varios tratamientos con el fin de que el señor Salomón fuese padre, a pesar que no se conocían personalmente y su único contacto había sido telefónico. La señora Saraí accedió y procedió a realizarse un tratamiento de fertilización in vitro en el Centro Imbanaco de Cali con sus propios óvulos y los espermatozoides del señor Salomón, el cual dio como resultado un embarazo gemelar. Salomón pagaba la EPS de Saraí y le enviaba mensualmente la suma de \$149.000 para su manutención, por lo que el juez de primera instancia se refiere al caso como un caso de contrato verbal de alquiler de vientres. (Corte Constitucional, sentencia T-968/09).

\section{Fecundación post-mortem}

El caso de una mujer que quiere quedar embarazada de un hombre que falleció en el 2008 genera un dilema ético y revela un vacío jurídico en el país. Si naciera el bebé de María Romero"* (una profesora barranquillera de preescolar), estaría destinado a ser el hijo de un muerto ya que a pesar de que Antonio*(un empresario español, 20 años mayor que ella, que se conocieron en el 2004 a través de Internet) su esposo falleció en el 2008, esta sigue soñando en tener un hijo suyo, y con la ciencia médica disponible actualmente podría lograrlo a través de una práctica conocida como inseminación post mórtem, ya que hay muestras congeladas del semen de Antonio, pero la clínica que las tiene se niega a hacerlo y a entregar el esperma, entre otras razones por la oposición que hacen dos (2) hijos españoles de Antonio

7 Decimos aproximado porque La Corte Constitucional Colombiana precisó, al final, que el processo que culunino con e I nacimientio de

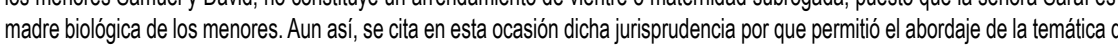
alquiler de vientres por la Corte Constitucional Colombiana.

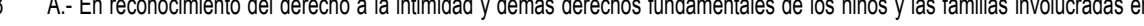
presente processo, la Corte decidió cambiar en esta providencia los nombres reales de los menores y sus familiares más cercanos,

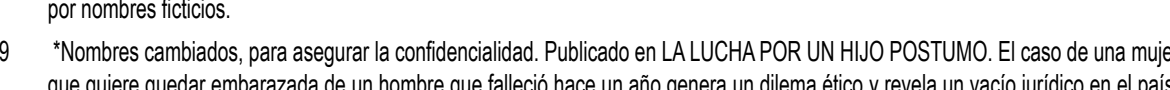

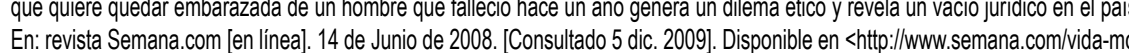

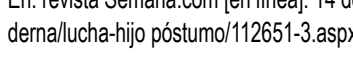


de su anterior matrimonio, por lo que María comenzó una batalla legal que por ahora va perdiendo. María instaura una acción de tutela invocando los derechos al libre desarrollo de la personalidad y a conformar una familia, la cual fue rechazada en dos oportunidades por juzgados de Barranquilla, en dos fallos que, de conformidad con el concepto del abogado de María, carecen de todo el rigor jurídico que ameritaba el tema, y paradójicamente la Corte Constitucional no escogió dicha acción de tutela para revisión. Vale la pena referenciar el antecedente jurisprudencial del caso Acosta-Vaca fallado por el juzgado 3 de familia de Bogotá, confirmado por sala de familia del tribunal superior de Bogotá el 2 de agosto de 1994.

\section{Concepto de Familia, según la jurisprudencia actual de la Corte}

\section{Constitucional Colombiana.}

Como punto de partida se debe señalar que, en la actualidad, la Corte Constitucional Colombiana, como desarrollo del nuevo modelo constitucional, ha incorporado nuevos modelos y diversas formas de familia colombianas, asi:

"Ahora bien, la presunción a favor de la "familia biológica" también puede ceder ante la denominada "familia de crianza", que surge cuando "un menor ha sido separado de su familia biológica y ha sido cuidado por una familia distinta durante un periodo de tiempo lo suficientemente largo como para que se hayan desarrollado vínculos afectivos entre el menor y los integrantes de dicha familia"...A las anteriores formas de familia se suman aquellas denominadas monoparentales, debido a que están conformadas por un solo progenitor, junto con los hijos y su número va en aumento por distintas causas, incluida la violencia que azota a un país como el nuestro y también el divorcio o las separaciones que dan lugar a hogares encabezados por uno solo de los padres, siendo evidente que el caso de las madres cabeza de familia es dominante y ha merecido la atención del legislador... También suele acontecer que después del divorcio o de la separación se consoliden nuevas uniones, en cuyo caso se da lugar a las llamadas "familias ensambladas", que han sido definidas como "la estructura familiar originada en el matrimonio o unión de hecho de una pareja, en la cual uno 0 ambos de sus integrantes tiene hijos provenientes de un casamiento o relación previa". (Corte Constitucional, sentencia

$$
\text { C-577 /11). }
$$

Consideramos que estudiar instituciones que datan de la época de redacción del código civil, tiene su mérito, pero en este escrito nos proponemos algo más, como lo es analizar aspectos novedosos que impacta en la nueva familia del siglo XXI, en una nueva forma de filiación, en la libertad o limitantes que existen a nivel legal para acudir a técnicas de reproducción asistida ya por parejas heterosexuales u homosexuales, y de esta manera se expresa nuestro criterio en cuanto a la pertinencia de la normativa del derecho de familia en el S. XIX, sobre un aspecto poco comentado y discutido en la actualidad colombiana. No se debe perder de vista como generador de la problemátic que nos ocupa, que el Código Civil, máximo instrumento de codificación de las relaciones entre los particulares, fue sancionado el 26 de mayo de 1873, hace más de un siglo, razón por la cual no pudo haber regulado aspectos que son de reciente desarrollo. Sin embargo, es cuestionable que el legislador actual, aún a pesar de conocer de los adelantos biotecnológicos y médicos, no se haya dedicado a dar respuesta a los problemas que estos plantean a la ciencia jurídica.(Moadie, 2012)10

\section{Familias homoparentales}

Resulta evidente precisar que a partir de la Sentencia C- 577 de 2011 proferida el 26 de julio del mimo año, con el Dr. Gabriel Eduardo Mendoza Martelo como Magistrado Ponente, se obtuvo el visto bueno de la Corte Constitucional Colombiana para la conformación de la familia homoparental; motivado lo anterior por la necesidad de decidir la demanda de inconstitucionalidad que interpusieron reconocidos constitucionalistas y activistas ${ }^{11}$ en contra de algunas expresiones contenidas en el artículo 113 del Código Civil( matrimonio heterosexual), en el inciso 10 del artículo 20 de la Ley 294 de 1996 y en el inciso 10 del artículo 20 de la Ley 1361 de 2009;

10 Algunos de los avances médicos que le representan problemas al la ciencia juridica son, entre otros: la investigación cientifica

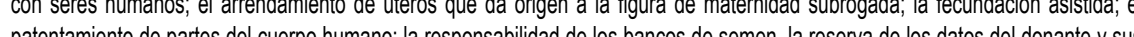

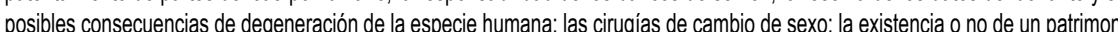
genếico; la donación de órganoss; el congelamiento de cadáveress; la fecundación post mórtem,; temáticas que se ha abordado en gros articulos productos de esta investigación.

11 El ciudadadno Carlos Andrés Echeverry Restrepo demandóa algunas expresiones del articulo 113 del Código Civily, de otra parte, los

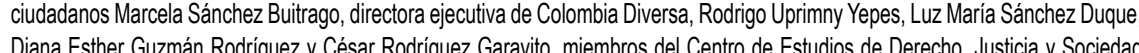
DEJUSTICIA, Mauricio Noouerar Roiass, abogado de Colombia Diversa, asi como Felipe Montova, Felipe Arias OSspina Juan Migued Eslava Lozzi y Juliana Emilia Galindo VVilareal, demandaron aluunas expressiones contenidas en el articulo 113 del Código Civil, en el inciso $1^{\circ}$ del articullo $2^{\circ}$ de l a Ley 294 de 1996 y en el inciso $11^{\circ}$ del articullo $2^{\circ}$ de la Ley 1361 de 2009. 
Entre tantos argumentos se esgrimió que, a la luz de la interpretación del artículo 42 de la Carta, el artículo 113 del Código civil acusado favorece "un trato desigual e injustificado, totalmente violatorio de lo dispuesto en el artículo 13 Superior que establece, claramente, que todas las personas deben recibir igual trato por parte de las autoridades asi como serles garantizados el disfrute de los mismos derechos, en este caso, el goce del derecho del matrimonio, de celebrar un contrato con su pareja que sea reconocido, públicamente, tanto por la legislación civil como por la sociedad, con el fin de ir derrumbando prejuicios inaceptables sobre un subgrupo (homosexuales) tradicionalmente discriminado y marginado".(Corte Constitucional Colombiana, Sentencia C-577 de 2011)

En esa ocasión la Corte Constitucional Colombiana en su parte resolutiva consideró:

i.) Declarar EXEQUIBLE, la expresión "un hombre y una mujer", contenida en el artículo 113 del Código Civil. ii.) Declararse INHIBIDA para pronunciarse de fondo respecto de la expresión "de procrear, contenida en el artículo 113 del Código Civil. iii.) Declararse INHIBIDA para pronunciarse de fondo respecto de la expresión "de un hombre y una mujer" contenida en los artículos 20 de la Ley 294 de 1996 y 20 de la Ley 1361 de 2009, por cuanto estas normas legales reproducen preceptos constitucionales. iv.) EXHORTAR al Congreso de la República para que antes del 20 de junio de 2013 legisle, de manera sistemática y organizada, sobre los derechos de las parejas del mismo sexo con la finalidad de eliminar el déficit de protección que, según los términos de esta sentencia, afecta a las mencionadas parejas. v.) Declarar que Si el 20 de junio de 2013 el Congreso de la República no ha expedido la legislación correspondiente, las parejas del mismo sexo podrán acudir ante notario o juez competente a formalizar y solemnizar su vínculo contractual.

Es evidente entonces, que La Corte Constitucional Colombiana declara el art 113 del Código civil exequible pero se declara inhibida de pronunciarse de fondo respecto del "matrimonio homosexual", exhortando a que lo haga el Congreso de la Republica, argumentando que NO le atañe a la Corte tomar la decisión acerca de la opción que está llamada a garantizar la existencia de la posibilidad de optar en el caso de las parejas homosexuales decididas a conformar familia ni del desarrollo concreto de dicha institución, lo cual si le corresponde al congreso porque este es el foro democrático por excelencia, y porque al ser la familia la institución básica y núcleo fundamental de la sociedad, su trascendencia social impone que su protección se otorgue mediante medidas que el órgano representativo (Congreso) debe asumir.

Pero lo que se quiere resaltar, en esta ocasión, es que a pesar de lo anterior lo que si dejo claro la Corte Constitucional Colombiana fue que partir de dicha sentencia SI se concibió el concepto jurisprudencial de la existencia de una familia homoparental, cuando expresó reiterativamente:

.."En lo referente a las interpretaciones del artículo 42 de la Constitución, ..., es suficiente recordar que la Corte ha replanteado la interpretación del citado precepto constitucional, lo que la ha conducido a reconocer la familia integrada por la pareja homosexual estable y a sostener que constitucionalmente existe una exigencia de superar el comprobado régimen de protección mediante la introducción de una figura jurídica que permita a las parejas conformadas por homosexuales optar por una form contractual solemne de constituir su unión, distinta de la unión de hecho que, aunque actualmente está a su disposición, no alcanza a superar el déficit advertido en esta sentencia. (Subrayado y negrillas propias)

...El reconocimiento constitucional del matrimonio para los heterosexuales y su consiguiente protección expresamente contemplada en la Carta no implican, necesariamente, la prohibición de prever una institución que favorezca la constitución de la familia integrada por la pareja homosexual de conformidad con un vínculo jurídicamente regulado. (Subrayado y negrillas propias)

...En esas condiciones, la Corte estima factible predicar que las parejas homosexuales también tienen derecho a decidir si consttuyen la familia de acuerdo con un régimen que les ofrezca mayor protección que la que pudiera brindarles una unión de hecho -a la que pueden acogerse si así les place-, ya que a la luz de lo que viene exigido constitucionalmente, procede establecer una institución contractual como forma de dar origen a la familia homosexual de un modo distinto a la unión de hecho y a fin de garantizar el derecho al libre desarrollo de la personalidad, asi como de superar el défici de protección padecido por los homosexuales".... (Subrayado y negrillas propias) 
Así las cosas, y como se puede observar, la existencia de la "familia homoparental" era una realidad reconocida por la Corte, y la lucha debía seguir en torno a la "forma legal de conformación de la familia homoparental", que hasta el momento solo era a través de la unión marital de hecho, -y no por mandato legal sino por mandato jurisprudencial, lo cual se obtuvo a través de la sentencia C-075 de 2007-, pero más allá de esa posibilidad ya reconocida con anterioridad, la Corte Constitucional Colombiana en esta ocasión sugirió una "forma contractual solemne distinta de la unión de hecho" para las parejas del mismo sexo, por lo que exhortó al Congreso de la Republica para que de manera sistemática y organizada legislara sobre los derechos de las parejas del mismo sexo con la finalidad de eliminar el déficit de protección que afecta a las mencionadas parejas, y en consecuencia concedió un plazo de 2 años para dicho fin, de manera tal que si el 20 de junio de 2013 el Congreso de la República NO había expedido la legislación correspondiente, las parejas del mismo sexo SI podrán acudir ante notario o juez competente a formalizar y solemnizar su vínculo contractual.

Aun así, es conocido que en el intervalo entre el 26 de julio de 2011 y el 20 de julio de 2013(plazo concedido por la Corte Constitucional al Congreso en la sentencia C-577 de 2011, y peor aún, luego del cumplimiento de dicho plazo, se propició una etapa traumática y desorientadora para las parejas del mismo sexo, toda vez que las autoridades encargadas no protegían sus derechos, y no se daba cumplimiento a los ordenado por la Corte, ocurriendo algunas de las siguientes actuaciones de las autoridades:

i) jueces o notarios que se negaban a realizar el contrato de matrimonio civil entre parejas del mismo sexo, ii) jueces o notarios que si realizan un contrato entre parejas del mismo sexo, pero no un contrato de matrimonio civil, sino un " contrato innominado", iii) jueves que anulaban matrimonios igualitarios alegando la existencia de un error sobre la identidad de género de uno de los contrayentes, iv) una Procuraduría General de la nación que comenzó una batalla de persecución jurídica contra los notarios o jueces que accedían a la solicitud de matrimonio civil de parejas del mismo sexo, y v) una negativa de los registradores que se negaban a inscribir matrimonio civil de parejas del mismo sexo que realizaban algunos jueces o notarios que si se arriesgaban a dar cumplimiento a la celebración de un contrato de matrimonio civil igualitario.

\section{CONFIGURACION FAMILIAR HOMOPARENTAL: de la claridad en materia de "familia homoparental" a la claridad en materia de "matrimonio igualitario entre parejas del mismo sexo". La histórica sentencia de unificación SU 214/2016.}

Ante la claridad ofrecida por la sentencia C-577 de 2011 en la que reconoce existencia de la FAMILIA HOMOPARENTAL, solo era necesario la claridad SOBRE EL MATRIMONIO CIVIL ENTRE PAREJAS DEL MISMO SEXO, motivado por las situaciones fácticas narradas con anterioridad, por lo que una vez más, la corte Constitucional Colombiana es protagonista cuando para brindar seguridad juridica y ante hechos reales y motivadores, le correspondió poner el punto final al tema del matrimonio entre parejas del mismo sexo, cuando emitió la que se ha denominado "la histórica sentencia SU 214 de 2016", unificando el tema, con ponencia del magistrado Alberto Rojas Ríos.

En esta ocasión la Sala Plena de la Corte Constitucional en una sentencia de 339 páginas (incluidos los anexos e intervenciones) resolvió seis (6) expedientes acumulados de tutela' ${ }^{12}$, esto indica que eran casos reales, en los que era necesario un pronunciamiento de la Corte, ante las incertidumbres y abuso de autoridades de los organismos que se negaban a realizar lo ordenado en la sentencia C 577 de 2011, en la que se planteó el siguiente problema jurídico, de carácter general: ¿celebrar un contrato civil de matrimonio entre parejas del mismo sexo, en lugar de una unión solemne innominada, con miras a suplir el déficit de protección declarado por la Corte en Sentencia C-577 de 2011, configura una violación del artículo 42 Superior, tal y como lo aducen quienes se negaron a celebrar o a registrar los matrimonios civiles igualitarios?; por el contrario, como lo interpretaron los jueces civiles que los celebraron ¿constituye una adecuada interpretación de la Sentencia C-577 de 2011, un ejercicio válido de autonomía judicial y una materialización de principios constitucionales como la igualdad, la libertad y la dignidad humana?

\section{Derecho comparado sobre matrimonio homoafectivo de acuerdo con la SU} 214/16.

La Corte Constitucional utiliza en la referida sentencia SU 214 de 20016, como uno de los fundamentos para su tomar decisión de permitir el matrimonio

12 I) (tutela formulada por una pareal integradad por un transsenerista y una muier contra la decisión del Juzaado Primero Promiscuo Municipal de La Dorada, Caldas, en el sentido de anular su mattimonio civil); ili) (amparo interpuesto por la Procurraduria General de la Nación contra el Juzgado Cuarenta y Ocho (48) Civil Municipal de Bogotía, que aceptí una petición de matrimonio de una pareja del

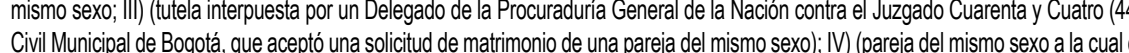

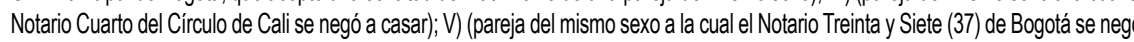
casar); YVI) (negativa del Registrador Auxiliar de Teusagaillo de inscribir un matimonio civile en el Registro del Estado C Ciil). 
igualitario en Colombia, el avance del derecho de las parejas del mismo sexo a contraer matrimonio en el derecho comparado, manifestando que "en un período de tan sólo quince años la humanidad, de forma gradual y progresiva, ha reconocido diversos derechos de las parejas del mismo sexo, entre ellos, el derecho a contraer matrimonio civil".

Manifestó la Corte, que de los ciento noventa y cuatro (194) Estados oficialmente reconocidos por la ONU, veintitrés (23) de ellos han aprobado el matrimonio entre personas del mismo sexo, explicitando que es posible observar tres vías o fuentes jurídicas diferentes entre sí de dicho reconocimiento, a partir de las cuales cada Estado ha condenado los tratos diferenciados basados en la orientación sexual por lo que ha permitido las uniones homoafectivas, entre ellas el matrimonio, asi:

- "países que permiten el matrimonio entre personas del mismo sexo, como consecuencia de decisiones judiciale ${ }^{13}$ adoptadas por los respectivos organismos judiciales. En algunos casos, posteriormente, se aprobaron leyes que legalizaron el matrimonio homosexual

- Estados que aprobaron el matrimonio entre parejas del mismo sexo vía legislativat4 y seguidamente, en ciertos casos, se profirieron fallos judiciales que declararon la constitucionalidad de las leyes aprobatorias; $y$

- Estados que, aunque de manera deficitariat5 reconocen uniones alternas al matrimonio, aun asi otorgan personalidad o protección jurídica a las parejas del mismo sexo."

(Corte Constitucional Colombiana, sentencia SU 214 de 2016)

13 El matimononio entre personas del mismo sexo está permitido por decisión judicical seis ( 6 ) paises, estos son: Canadáa (2004),

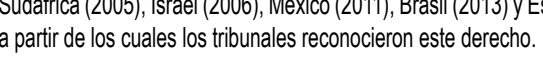

14 El matrimoni entre personas del miemo (2001), Bélgica (2003), España (2005), Norruega (2008), Suecia (2009), Uruguaray (2009), Portugal (2010). Argentina (2010), Islandia (2010), Dinamarca (2010), Francia (2013), Nueva Zelanda (2013), Finandia (2014), Luxemburgo (2014), Inglaterra, Galesy Escocia (2014), y, en un(1) solo caso este derecho frue aprobado mediante referendo (rlanda).

15 Otro grupo de Estados han expedido una reglamentacición diversa para reconocecr las uniones entre personas del mismo sexo, en

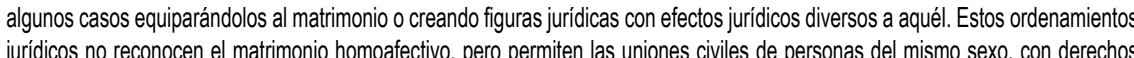
similaress a los del matrimonio, aunnue sin esa denominanación. Es el caso de países como: Italia, Alemania, Austria, Croacia, Estonia, Hungria, Suiza, Malta, Ia Repuiblica Checa, algunas regiones de Australia, entre otros.
Para la solución de los diversos problemas jurídicos la Corte aplicó subreglas constitucionales, manifestando que encontraron su fundamento en varios siguientes elementos interpretativos, de los cuales es importante resaltar algunos apartes, a propósito del tema desarrollado en este artículo:

* La Corte considera que es una contradicción evidente afirmar que las parejas del mismo sexo constituyen familia, pero que para contraer un vínculo marital y solemne, deban hacerlo recurriendo a una figura jurídica no sólo diferente de aquella aplicable para las parejas heteroafectivas, sino con efectos jurídicos reducidos e inciertos (contrato civil innominado), Una interpretación sistemática basada en el "derecho viviente", y en procura de los derechos de las minorías, no admite la existencia de dos clases de matrimonio, enviando un mensaje de inferioridad a algunas personas,

*Se señaló la Competencia de la Corte Constitucional ante omisión legislativa, se funda en el principio de protección de los derechos fundamentales de grupos minoritarios, la Sala Plena verificó que el Congreso de la República ha omitido regular las relaciones jurídicas derivadas de las diversas modalidades de uniones de convivencia de las parejas del mismo sexo. Desde 1999 a la fecha, se han archivado 0 retirado - en algunas ocasiones sin discusión alguna18 proyectos de ley del más variado alcance y naturaleza, que buscaban suplir el déficit de protección, tantas veces reclamado mediante la normalización y la nominación jurídico-dispositiva de las comunidades de vida de aquéllas.

*Se realizó una determinación del significado de la palabra "matrimonio". Siguiendo a Wittgenstein ${ }^{16}$, la Corte constató que la configuración del concepto de "matrimonio" responde no sólo a la representación de un hecho social, sino que envuelve un conjunto de valores, cargas afectivas y relaciones de poder existentes en un determinada sociedad. Se trata, en consecuencia, de una noción evolutiva, cuyos elementos y comprensión ha variado con el correr de los años.

*Matrimonio como programa de vida, Hoy por hoy, las expresiones "matrimonio", "relación matrimonial", "celebración de matrimonio" "consumación y consolidación matrimonial", etcétera, corresponden

16 Wittgenstein, Tractatus Lógico-Philosophicus, Paris, Gallimard, 1961. 
a diversas expresiones que definen en común derechos fundamentales, que implican culturalmente la disposición de un programa de vida compartida por individuos de la especie humana.

*Se señaló que la sexualidad y la procreación son fines, más no elementos esenciales del matrimonio. El quid iuris del matrimonio no se determina por quienes lo conforman, sino por la finalidad que representa el libre ejercicio del derecho a formar una comunidad de vida. El objetivo constitucionalmente perseguido por el matrimonio es constituir la familia, que es el núcleo fundamental de la sociedad

Es de resaltar de la parte resolutiva de la sentencia en mención el numeral 8 que reza:

“OCTAVO. EXTENDER, con efectos inter pares, la presente sentencia de unificación, a todas las parejas del mismo sexo que, con posterioridad al veinte (20) de junio de 2013: (i) hayan acudido ante los jueces o notarios del país y se les haya negado la celebración de un matrimonio civil, debido a su orientación sexual; (ii) hayan celebrado un contrato para formalizar y solemnizar su vínculo, sin la denominación ni los efectos jurídicos de un matrimonio civil; (iii) habiendo celebrado un matrimonio civil, la Registraduría Nacional del Estado Civil se haya negado a inscribirlo y; (iv) en adelante, formalicen y solemnicen su vínculo mediante matrimonio civil, bien ante Jueces Civiles Municipales, ora ante Notarios Públicos, 0 ante los servidores públicos que llegaren a hacer sus veces."( Corte Constitucional Colombiana, SU 214 de 2016)

De igual manera, se debe resaltar de la parte resolutiva de la sentencia: i).La declaración contundente de que los matrimonios civiles celebrados entre parejas del mismo sexo, con posterioridad al veinte (20) de junio de 2013, gozan de plena validez jurídica, ii)La defensa que hizo de los jueces de la República, que se arriesgaron a celebrar matrimonios civiles entre parejas del mismo sexo en Colombia, manifestando que ellos $\mathrm{SI}$ actuaron en los precisos términos de la Carta Política y en aplicación del principio constitucional de la autonomía judicial, iii)La advertencia a las autoridades judiciales, a los Notarios Públicos, a los Registradores del Estado Civil del país, y a los servidores público en el sentido que el fallo de unificación tiene carácter vincu- lante, con efectos inter pares, iv)La orden a la Sala Administrativa del Consejo Superior de la Judicatura, a la Superintendencia de Notariado y Registro y a la Registraduría Nacional del Estado Civil, de adopción de medidas de difusión del fallo entre los Jueces, Notarios Públicos y Registradores del Estado Civil del país.

\section{La Reproducción asistida, un desafio para las parejas heterosexuales y}

\section{homosexuales}

El acceso a las técnicas de reproducción humana asistida como un derecho es en Colombia un desafío, aun para las parejas heterosexuales, asi que con muchas más razones lo serán para las parejas del mismo sexo.

Si bien Colombia es un país que cuenta con avances médicos en materia de reproducción asistida, las parejas heterosexuales enfrentan retos para acceder a la procreación a través de dichas técnicas, en especial porque e sistema de Plan obligatorio de salud, cuenta con criterios de exclusión para otorgar el acceso a dichos tratamientos, ha sido la Corte Constitucional quien ha planteado a través de la jurisprudencia, avances en materia de acceso a las técnicas de reproducción humana asistida, bajo ciertas condiciones ${ }^{17}$;

Se sugiere entonces que si esto es así para parejas heterosexuales, con muchas más razones será complejo el acceso a las técnicas de reproducción asistida para parejas homosexuales, máxime si se tiene en cuenta que la historia de reconocimientos de derechos a parejas del mismo sexo en Colombia ha demostrado que han tenido un reconocimiento tardío y solo vía jurisprudencial, toda vez que los derechos concedidos vía legal a los heterosexuales solo han sido extendidos de manera igualitaria con una gran distancia en e tiempo y por la vía jurisprudencial a los homosexuales, siendo la excepción en materia de derechos patrimoniales el derecho a la porción conyuga $l^{18} \mathrm{y} e$ derecho de herencia ${ }^{19}$, que les fue concedido jurisprudencialmente al mismo tiempo a compañeros permanentes heterosexuales y a parejas del mismo sexo, como una extensión de garantía patrimonial a parejas homosexuales cuando le fue reconocida a los heterosexuales.

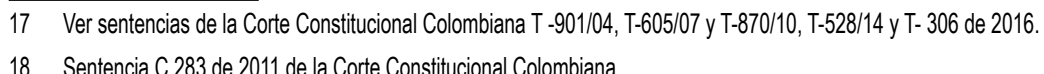

18 Sentencia 283 de 2011 de la Corte Constitucional Colombiann

19 Sentencia 238 de 2012 de la Corte Consititucional Colombiana 
Es necesario manifestar, que los países que han avanzado en materia de matrimonio igualitario tiempo después como un efecto dominó se plantean la necesidad del acceso a las técnicas de reproducción asistida por parte de las parejas del mismo sexo. De igual manera en los países que cuentan con avanzadas y actuales legislaciones, las técnicas de procreación humana asistidas están permitidas no necesariamente para matrimonios, sino para parejas sin el mencionado vínculo, o aun para la utilización de personas individuales, o para parejas del mismo sexo, por ejemplo:

En España la moderna ley 14 de $2006^{20}$ en su art. 6, señala como usuarios del servicio, a toda mujer mayor de 18 años con plena capacidad de obrar podrá ser receptora de las técnicas reguladas, con independencia de su estado civil y orientación sexual, y establece reglas en caso de estar casada en cuanto al consentimiento de su marido, y en todo caso establece el régimen de filiación para los hijos nacidos mediante técnicas de reproducción asistida.

En Argentina mediante la ley No. 29.994, entró en vigencia el 1 de agosto de 2015, el nuevo Código Civil y Comercial de la nación Argentina, en el que en relación con la filiación en su título V dedica el capítulo 2 a las "reglas generales relativas a la filiación por técnicas de reproducción humana asistida" y se refiere sin discriminar "a las personas que se sometan al uso de las técnicas de reproducción humana asistida", lo cual es entendible si se tiene en cuenta que Argentina es el primer País de Latinoamérica y el décimo a nivel mundial que aprobó vía legislativa el "matrimonio igualitario"-como se llamó en Colombia- mediante la Ley 26.618 del 21 de Julio en el año 2010, esto es, cinco ( 5 ) años antes de la expedición del referido nuevo código civil.

En Colombia, teniendo en cuenta la omisión legislativa sobre el acceso a las técnicas de reproducción humana asistida, no se debe permitir que cuando por fin se reglamenten se plantee vía legislativa una "exclusión reproductiva a parejas del mismo sexo"; todo lo explicado anteriormente en cuanto a la vigencia y aprobación jurisprudencial de la "familia homoafectiva" y del "matrimonio igualitario", así como de "la adopción por parte de parejas del mismo sexo"21 NO sugieren un trato discriminatorio en dicho sentido, de tal manera que al legislarse sobre el acceso a las técnicas se debe propugnar por el derecho a la igualdad, a la dignidad, a la no discriminación, a la libertad 20 Ley 14 de 2000,26 de mayo; España, enitida por la Jéatura de Estado, en el boletin oficial del Estado número 126, 270552006. 21 Ver sentencias T-276 de 2012, C-C63 de 2015, C-071 de 2015 y autodeterminación, al libre desarrollo de la personalidad, a la intimidad personal y familiar, y a la salud y autonomía reproductiva, y el derecho a conformar una familia.

Así las cosas, teniendo en cuenta que en Colombia hay una ausencia de legislación en materia de técnicas de reproducción humana asistida, se puede manifestar que las TRA que están científicamente disponibles para las parejas de la comunidad LGBTI serían las mismas a los que podría recurrir una pareja heterosexual: donación de óvulos y semen, inseminación artificial, fecundación invitro, arrendamiento de vientre, aunque es preciso distinguir entre las técnicas de reproducción asistida la más propicia para cada pareja de miembros de la comunidad LGTBI.

\section{Parejas homosexuales femeninas( lesbianas)}

Las parejas del mismo sexo femeninas-lesbianas- de acudir a las TRA, les resulta beneficioso para sus fines, someterse a la técnica de fecundación in vitro y acudir a la donación de semen anónimo $0^{22}$, mediante el método denominado por sus siglas, ROPA (Recepción de Ovocitos de la Pareja), de este modo, una de las lesbianas proporciona los óvulos se fertilizan con el semen del donante anónimo ( heteróloga) y los embriones se transfieren a la otra mujer de la pareja en la que se realiza la gestación y el parto. Así, se cree que la maternidad es conjunta, ya que el tratamiento se comparte entre pareja, En este caso de acudirse a inseminación artificial o fecundación invitro tendría que ser heteróloga, esto es, cuando el semen fecundante para obtener la concepción corresponde a un tercero donante

\section{Parejas homosexuales masculinas (gays)}

Las parejas del mismo sexo masculinas-gays- de acudir a las TRA, les resulta beneficioso para sus fines, someterse a la técnica de arrendamiento de vientres, con donación de óvulos a través de inseminación artificial o fecundación invitro.

Por lo anteriormente explicado -que será producto de un desarrollo extensivo en otra fase de la investigación-, es preciso concluir que cada uno de los miembros de la comunidad LGTBI debe escoger entre la gama de técnicas de

22 En otras ocasiones hemos tenidol la oportunidad de trabajar en articulo próximo a ser publicado, que se ha titulado: "Reflexión ncritica sobre el Principio de anonimidad en los datos del donanate en técnicas de reproducción asistida." 
reproducción humana asistida las que resulten idóneas de acuerdo con las especificidades del sistema reproductivo con el que cuente la pareja, por lo que nos proponemos próximamente identificar retos y desafíos jurídicos en la implementación de las Técnicas de reproducción humana asistida utilizadas por parejas de lesbianas y de Gays.

\section{CONCLUSIONES}

A manera de conclusiones proponemos, inicialmente reconocer que no es novedoso el discurso en torno a la viabilidad y conveniencia de la acogida de las técnicas de reproducción humana asistida, pero sí es novedoso analizar las consecuencias jurídicas que se derivan de la aplicación de las mismas y el impacto que estas pueden tener en una nueva conformación de la familia.

ustificado el porqué de la ausencia de regulación inicial en el Código Civil en cuanto a las técnicas de reproducción humana asistida, del acceso a las técnicas como un derechos de las parejas heterosexuales y homosexuales y del impacto en la conformación de un novedoso concepto de familia, con un énfasis "la conformación de las familias homoparentales a través de las T.R.A." resultado de mezclar dos categorías: una primera categoría de familia homoparental y una segunda categoría de utilización de técnicas de reproducción asistida ( T.R.A.) para la conformación de dicha familia homoparental, no se exime al legislador de la misión que tiene en la actualidad.

Sin lugar a dudas no es tarea fácil legislar en esta materia, las tensiones argumentativas reflejadas en el desarrollo de este texto así lo confirman(Moadie, 2015); En este sentido "el legislador teme con razón, que la sociedad humana pueda hundirse en el medio de tempestades desencadenadas por la biotecnología. Pero lo que le aterra en lo inmediato es dar respuestas que sean, o demasiado restrictivas para los científicos, o demasiado débiles para la garantías de la dignidad de la persona. De este modo se encuentra entre dos peñascos, sin saber cómo hacer para avanzar satisfaciendo exigencias que parecen contradictorias." (ADORNO, 1998)

La ciencia no se detiene, por lo tanto, ante los avances de la ciencia médica, el silencio del legislador es cuestionable, porque abre una brecha entre esta y la ciencia jurídica, resultando apremiante la necesidad de plantearse nuevas reflexiones y normas que cobijen las posibles soluciones a los desafíos que plantea la aplicación de las técnicas de reproducción humana asistida permi- tidas por la Constitución Política Colombiana para de esa manera aproximarse a un novedoso concepto de familia conformada a través de las técnicas de reproducción asistida en Colombia, con un especial énfasis en la conformación de las familias homoparentales a través de las T.R.A. ¿Utopía o realidad?

\section{REFERENCIAS BIBLIOGRÁFICAS.}

Adorno, R. (1998). Bioética y dignidad de la persona. Madrid. Editorial: Tecnos.

Flores Salgado, L(2007). Reflexión ético jurídica sobre las técnicas de reproducción P113. disponible

Moadie Ortega V. (2012) "Principio de dignidad humana en el arrendamiento de DFilippo Facultad de Derecho de la Universidad de Cartagena volumen 4 revista No. 1, ejemplar No. 7, primer semestre de 2012, ISSN 2145-6054. ISSN (electrónico) 2256-2796

Moadie Vanina, (2014) Reflexión crítica sobre la fecundación post-mortem en el ordenamiento jurídico colombiano y su incidencia en el ámbito filial y sucesoral,
En:Perspectivas y avances en el derecho desde la investigación socio jurídica, Editorial tecnológico Comfenalco, Pag. 640 a 660 ISBN:978-958-58454-6-6.

Moadie Vanina( 2015) Reflexión crítica sobre la fecundación post-mortem como técnica de reproducción asistida en el ordenamiento jurídico colombiano y su incidencia en el ámbito filial y sucesoral. XI Jornadas de Sociología. Facultad de Ciencias Sociales, Universidad de Buenos Aires, Buenos Aires, 2015. http://cdsa. aacademica.org/000-061/327.

Santamaría Solís, (2000). Técnicas de reproducción asistida. Aspectos bioeticos. Disponible en http://aebioetica.org/revistas/2000/1/41/37.pdf

Sarmiento, P. J.(2009) "La técnica de reproducción asistida 25 años después. Persona y Bioética" Bogotá. Universidad de la sabana, 2009. Disponiblehti.//personaybioetica.unisabana.edu.co/index.php/personaybioetica/article/view/834/2012

CORTE CONSTITUCIONAL, Sentencia C.-075 de 2007, Magistrado ponente Jaime Araujo Rentería.

CORTE CONSTITUCIONAL. Sentencia T- 968 de diciembre 18 de 2009, M.P. María Victoria Calle Correa.

CORTE CONSTITUCIONAL, Sentencia C.-557 de 2011, de 26 de julio de 2011. Magistrado ponente Gabriel E. Mendoza $\mathrm{M}$.

CORTE CONSTITUCIONAL, Sentencia SU 214 de 2016, de 28 de abril de 2016. Magistrado ponente Alberto Rojas Ríos.

Corte Suprema de Justicia Colombiana, Sala de casación civil, Magistrado Ponente: Arturo Solarte Rodriguez, Bogotá, D.C., veintiocho (28) de febrero de dos mil trece (2013):-

Ley 14 de 2006, 26 de mayo; España, emitida por la Jefatura de Estado, en el boletin oficial del Estado número 126, 27/05/2006.

LA LUCHA POR UN HIJO POSTUMO. El caso de una mujer que quiere quedar embarazada de un hombre que falleció hace un año genera un dilema ético y revela un vacío jurídico en el país. En: revista Semana.com [en línea]. 14 de junio de 2008. [Consultado 5 dic. 2009]. Disponible en http://www.semana.com/vidamoderna/ lucha-hijo-postumo/112651-3.aspx

Proyecto de ley 151 de 2001, art 2, Senado de Colombia, por el cual se pretendió "modificar los códigos civil y Penal en lo referente a la aplicación de los métodos 
de procreación humana asistida, manipulación genética, se dictan normas sobre el genoma humano, de nuestra diversidad étnica, y otras disposiciones".

Constitución Política Colombiana, promulgada en 1991.

Código Civil Colombiano.

\section{Directrices para autores}

Vis luris (ISSN Impreso 2389-8364) es una publicación científica de periodicidad semestral, creada por iniciativa del grupo de investigación Joaquín Aaron Manjarrés, adscrito a la Escuela de Derecho de la Universidad Sergio Arboleda - seccional Santa Marta. Su primera edición fue publicada en el año 2014, momento en el cual se ha comprometido a presentar a la comunidad científica investigaciones de impacto nacional e internacional relacionadas con el Derecho y las Ciencias Sociales.

Vis luris está dirigida a juristas, investigadores, profesores, profesionales estudiantes de origen nacional e internacional que deseen publicar investigaciones relacionadas con el derecho administrativo, derecho penal y política criminal, derecho laboral, filosofía del derecho, ética del jurista, derech familiar, sociología jurídica, responsabilidad civil, historia de los sistemas jurídicos, derecho tributario, política y aquellos temas que sean coherentes con la ciencia del derecho. Su objetivo principal es publicar y difundir investigaciones inéditas y originales escritas en español e inglés que ayuden a la comprensión de lo que sucede en la actualidad de Latinoamérica, el Caribe u otros lugares del mundo donde se efectúen investigaciones que impacten en la región.

\section{PRESENTACIÓN DE ARTÍCULOS}

Vis luris recibe artículos de forma permanente, los cuales deben ir acompañado de la carta de presentación y cesión de derechos de artículos, la cual podrá solicitar a la revista o descargar en el portal de la misma. La dirección de envío de sus contribuciones es la siguiente: visiuris.sm@usa.edu. 